\title{
Antimicrobial peptides of buffalo and their role in host defenses
}

\author{
Khangembam Victoria Chanu ${ }^{1}$, Dimpal Thakuria ${ }^{1}$ and Satish Kumar ${ }^{2}$ \\ 1. ICAR-Directorate of Coldwater Fisheries Research, Bhimtal - 263 136, Uttarakhand, India; 2. ICAR-Indian Veterinary \\ Research Institute, Bareilly - 243 122, Uttar Pradesh, India. \\ Corresponding author: Dimpal Thakuria, e-mail: drdimpal@gmail.com \\ Co-authors: KVC: drvictoriachanu@rediffmail.com, SK: drsatishkumar_ivri@yahoo.co.in \\ Received: 07-10-2017, Accepted: 16-01-2018, Published online: 15-02-2018
}

doi: 10.14202/vetworld.2018.192-200 How to cite this article: Chanu KV, Thakuria D, Kumar S (2018) Antimicrobial peptides of buffalo and their role in host defenses, Veterinary World, 11(2): 192-200.

\begin{abstract}
Antimicrobial peptides (AMPs) are highly conserved components of the innate immune system found among all classes of life. Buffalo (Bubalus bubalis), an important livestock for milk and meat production, is known to have a better resistance to many diseases as compared to cattle. They are found to express many AMPs such as defensins, cathelicidins, and hepcidin which play an important role in neutralizing the invading pathogens. Buffalo AMPs exhibit broad-spectrum antimicrobial activity against both Gram-positive and Gram-negative bacteria. Similar to its natural form, synthetic analogs of buffalo AMPs are also antimicrobial against bacteria and even fungus making them a good target for the development of therapeutic antimicrobials. In addition to its antimicrobial effect, AMPs have been demonstrated to have a number of immunomodulatory functions, and their genes are responsive to infections. Further, induction of their gene expression by external factors may help in preventing infectious diseases. This review briefly discusses the AMPs of buffalo identified to date and their possible role in innate immunity.
\end{abstract}

Keywords: antimicrobial peptides, Bubalus bubalis, cathelicidins, defensin, hepcidin.

\section{Introduction}

Domestic water buffalo (Bubalus bubalis) is a major milk-producing animal in several countries and a significant contributor in global milk production (http://www.fao.org). India is the largest milk producing country, and as per the FAO 2009 statistics, $56.1 \%$ of total milk production in India is contributed by buffalo. India is also world's largest exporter of buffalo meat, which forms about $30 \%$ of total meat production in the country (http://ficci.in). According to the $19^{\text {th }}$ livestock census, 2012, the total number of buffalo in the country is 108.7 million showing a growth of 3.19\% since 2007 (http://dahd.nic.in). It showed that these animals are an important section of livestock wealth of the country. Water buffaloes are generally healthy animal considering the hot, humid environment where they live. Although these regions are favorable to infections, there is a less deleterious effect of diseases on buffalo as compared to that of cattle in the same ecosystem (http://www.buffalopedia.cirb.res.in). It indicates that buffaloes have a stronger innate immunity to fight against infection. It was also reported that buffalo polymorphonuclear cells contain an array of antimicrobial proteins and peptides which play a significant role in the immune defensive system [1]. Antimicrobial peptides (AMPs) are evolutionary conserved essential molecules of the innate

Copyright: Chanu, et al. Open Access. This article is distributed under the terms of the Creative Commons Attribution 4.0 International License (http://creativecommons.org/licenses/by/4.0/), which permits unrestricted use, distribution, and reproduction in any medium, provided you give appropriate credit to the original author(s) and the source, provide a link to the Creative Commons license, and indicate if changes were made. The Creative Commons Public Domain Dedication waiver (http://creativecommons.org/ publicdomain/zero/1.0/) applies to the data made available in this article, unless otherwise stated. immune system which are found among all classes of life. For example, bacteria produce bacteriocins to inhibit the growth of similar or closely related bacterial strain [2]. Certain fungi of Trichoderma genus produce peptaibols, peptides containing $\alpha$-aminoisobutyric acid, and ending in an alcohol [3]. Cecropins, first isolated from the hemolymph of Hyalophora cecropia, constitute the main part of cell-free immunity in insects [4]. Fish expresses a fish-specific class of the cecropin family, called piscidins [5]. Magainins and dermaseptins are AMPs isolated from frogs $[6,7]$. In avian species, cathelicidins and $\beta$-defensins are two major families of AMPs [8]. Cathelicidins and defensins also constitute the main mammalian AMPs [9].

In animals, AMPs are believed to be the first line of defense and are mostly found in the tissues and organs that are exposed to airborne pathogens $[9,10]$. AMPs have been demonstrated to kill bacteria, fungus, enveloped viruses, and even cancer cells [11-16]. In recent years, AMPs have gained the interest of many researchers because of its broad-spectrum activity against several pathogens and have been studied in different species. In buffalo, AMPs studied so far belong to defensins, cathelicidins, and hepcidin and new members are being discovered. Considering the importance of buffalo in livestock sector and beneficial effect of these naturally occurring molecules, this review provides an overview of AMPs identified in B. bubalis with their role in immunity.

\section{Defensins}

Defensins comprise an important family of AMPs. They are small (29-45 amino acid residues) cationic peptides that contain six conserved cysteine residues, which form three disulfide bonds [17]. Defensins 
are classified into alpha-, beta-, and theta-defensins based on size and pattern of disulfide bonding. Alphadefensins have been identified in humans, monkeys, and several rodent species. Theta-defensins are the only cyclic peptides of animal origin and are believed to have evolved from alpha-defensins [18]. They have been isolated from rhesus monkeys and baboons but not from humans, chimpanzees, and gorillas [19,20]. Beta-defensins have been found in every mammalian species explored so far and are involved in protecting the skin and the mucous membranes of the respiratory, genitourinary, and gastrointestinal tracts [20]. Betadefensins are encoded by genes consisting of two exons with the first exon encoding the signal sequence and the second encoding the propeptide and mature peptide [21]. They are synthesized as pre-propeptides and are post-translationally processed into mature, active peptides.

Alignment of primary amino acid sequences of defensins precursor sequences from buffalo shows that lingual AMP (LAP), tracheal AMP (TAP), enteric beta-defensin (EBD), and beta-defensin 4 (BD4) have high sequence identity (Figure-1). There was 100\% identity in the sequences of LAP isolated from mastitic udder (ABN72271), teat canal (AIU56268), and female reproductive tract (ABV01367) of buffalo. However, LAP from the tongue (ABE66309) showed only $87.5 \%$ identity with LAP from mastitic udder, teat canal, and female reproductive tract. EBD from distal ileum (AAP57565) exhibited 93.8\%, 92.2\%, 92.2\%, and $92.2 \%$, respectively, with LAP from tongue, mastitic udder, teat canal, and female reproductive tract. There was $100 \%$ identity in the sequences of BD4 from mastitic udder (ABN72273) and BD4 from teat canal (AIU56270). Neutrophil BD4 had an identity of $71.4 \%$ with LAP of mastitic udder, teat canal, and female reproductive tract. BD 120 (ARO77466) and BD119 (ARO77467) isolated from the uterus of Egyptian buffalo showed sequence identity lesser than $25 \%$ with other defensins in the alignment. TAP from teat canal (AIU56269) and TAP from mastitic udder (ABN72272) showed 100\% sequence identity. TAP from bovine was the first well-characterized member of the beta-defensin family [22]. It is a 38 amino acid peptide and the putative precursor was predicted to be 64 amino acids. The purified peptide showed broad-spectrum antimicrobial activity against
Escherichia coli, Staphylococcus aureus, Klebsiella pneumonia, Pseudomonas aeruginosa, and Candida albicans. In buffalo, cationic peptides from tracheal epithelial cells have been isolated and characterized [23]. The peptides were smaller than $10 \mathrm{kDa}$ and showed antibacterial activity against $E$. coli and Salmonella typhimurium. The antimicrobial activity of TAP is thought to result from disruption of bacterial membranes and pore formation which results from the electrostatic interaction of the positively charged peptide and negatively charged phospholipid of the bacterial membrane $[24,25]$. In tracheal tissues of buffalo, beta-defensin 4, beta-defensin 10, and beta-defensin 11 have also been identified [26]. Other than respiratory tract, TAP expression has also been found in teat canal mucosal epithelium and mastitic udder of buffalo $[27,28]$. This indicates that mucosal epithelial lining in buffalo is gifted with cationic AMPs to fight against microbial invasion.

LAP was first isolated from the inflamed tongue of cattle but found more extensively throughout the body and detected even in milk [29-31]. Expression of LAP selectively increases in inflamed areas showing a closer relationship with immune response than simple antimicrobial activity. In buffalo, LAP has been identified from different tissues [32-37]. Precursor protein of buffalo LAP is of 64 amino acids and the matured AMP is of 42 amino acids [35]. It has been suggested that mature active peptides are released quickly from precursor by proteolytic activity during microbial invasion $[38,39]$. The mature peptide has the characteristic features of beta-defensin family including six conserved cysteine residues. In addition to its eight positively charged and eight hydrophobic amino acids in the mature peptide of buffalo LAP, the presence of proline residues might be responsible for making it potent endogenous AMP (Figure-2). It has been documented that proline-rich peptide can enter the cell without membrane lysis, bind to the ribosome, and interfere with the process of protein synthesis [40,41]. Proline also enhances the microbicidal activity by forming flexible helical link which increases membrane permeability and allows the hydrophobic residues to reside in the concave helical region $[42,43]$. Synthetic analogs of buffalo LAP showed antimicrobial activity against $S$. aureus, Listeria monocytogens, E. coli, and S. typhimurium [44]. Beta-defensin

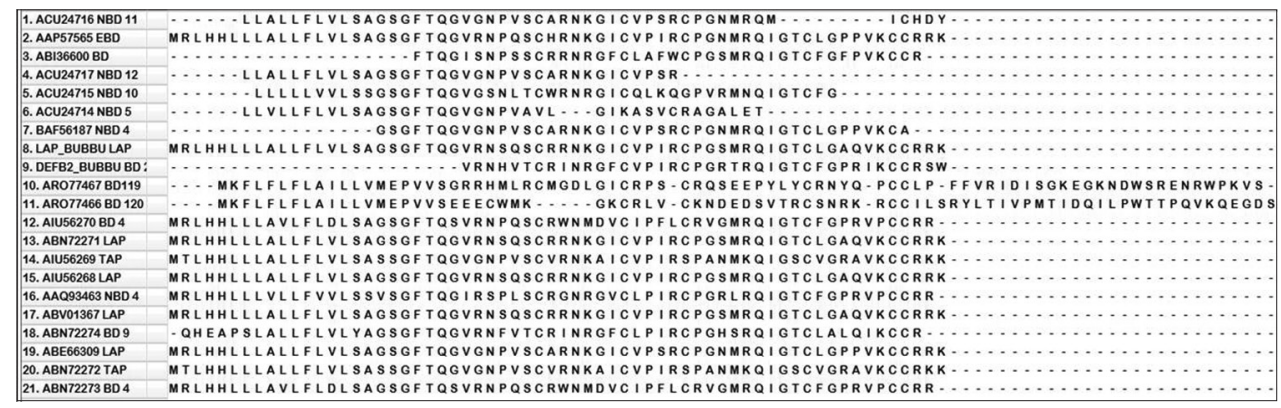

Figure-1: Alignment of beta defensin sequences of buffalo. Primary amino acid sequences with accession number were obtained from NCBI and aligned by ClustalW of MEGA 7.0 [97]. 


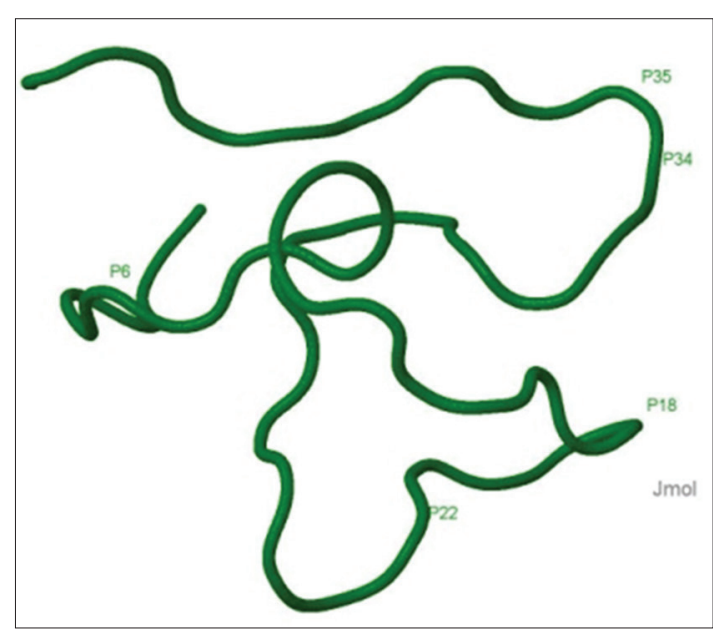

Figure-2: Predicted three-dimensional structure of buffalo lingual antimicrobial peptide (Accession number: ABE66309). The structure was predicted by PEP-FOLD and visualized in Jmol $[98,99]$. Proline residues are labeled on the molecule.

peptides, namely, LAP and BNBD-2 (Bovine neutrophil beta-defensin-2) isolated from mastitic milk of buffalo also showed significant antibacterial activity against $S$. aureus and E. coli [45]. The expression of these AMPs in the ductal epithelium of mammary gland might has been induced during mastitis leading to release of these peptides in the milk. As observed in the alignment of sequences, LAP identified in tissues other than the tongue of buffalo has reduced number of proline residues [32,33,35-37]; hence, a comparative study may be carried out to understand the role of proline in these AMPs. Another neutrophil beta-defensin, BNBD-4, was identified earlier from bone marrows of water buffalo [46]. From distal ileum of buffalo, EBD mRNA was characterized which encodes for a 64 amino acids precursor peptide [47]. EBD was first identified in the intestine of cattle and expressed highly in distal small intestine and colon, and its expression was inducible by gastrointestinal infection with Cryptosporidium parvum suggesting the participation of these molecules in local host defense of enteric mucosa [48]. In the mature peptide of buffalo EBD, the amino acids, serine (S), leucine $(\mathrm{L})$, and tryptophan $(\mathrm{W})$ at positions, 26, 33, and 63, respectively, of cattle EBD were found to be replaced by positively charged basic amino acid arginine (R). These substitutions increase the net positive charge of buffalo EBD and perhaps enhance the antimicrobial activity which may be correlated with better disease resistance in buffalo [47].

\section{Cathelicidins}

Cathelicidins are proteolytically activated small, cationic AMPs with broad-spectrum antimicrobial activity against bacteria, enveloped viruses, and fungi [49]. The name cathelicidin was given to this group of AMPs because its prosequences showed high sequence identity with the sequence of a protein termed cathelin, which is isolated from porcine leukocytes [50,51]. Cathelicidin precursors comprise in most cases, a highly identical N-terminal pre-prosequences and a variable $\mathrm{C}$-terminal antimicrobial domain. Matured cathelicidins are released by elastase enzyme by cleavage at a specific valine residue of the precursor [50]. In general, cathelicidins exhibit its antimicrobial activity by disintegrating the cell membrane of organisms [49]. Certain cathelicidins such as porcine cathelicidins PR-39 and indolicidin, a member of cathelicidin, were reported to inhibit protein synthesis and even induce the degradation of certain necessary proteins for DNA replication by the pathogen [52]. Indolicidin had been shown to bind DNA at preferred sequence, which may contribute to its antimicrobial action and can also inhibit topoisomerase 1, enzymes that cut one strand of double-stranded DNA, relax the strand, and reanneal the strand $[53,54]$.

Human and mice have only one cathelicidin gene while other mammals such as cow, sheep, pig, and rabbit can have many [55]. The first mammalian cathelicidins were bactenecins (Bac-5 and Bac-7) isolated from bovine neutrophil [56]. Both Bac-5 and Bac-7 efficiently kill E. coli, S. typhimurium, and K. pneumonia and arrest the growth of Enterobacter cloacae, S. aureus, and Streptococcus agalactiae. In buffalo, a cathelin-like $10.5 \mathrm{kDa}$ region of 91 residues was identified from myeloid cells [57]. Buffalo uterus also expresses cathelicidin which may prove to be a potent antimicrobial agent [58]. A number of cathelicidins have been identified in buffalo and the alignment of the sequences showed high variability at C-terminal antimicrobial domain (Figure-3). When cathelicidin 2 of buffalo (AJO90931) was compared with bovine cathelicidin 2 (CTHL2_BOVIN), a sequence diversity $8.4 \%$ was observed. Within the buffalo cathelicidins, probactenecin 7 from bone marrow (ACU86957) showed $33.5 \%, 28.5 \%$, and $28.4 \%$ sequence divergence to cathelicidins obtained from male reproductive organ (ABH09752), female reproductive tract (ABJ80585), and bone marrow (CAH23217), respectively. All the cathelicidins 4 (AIZ93887, AIZ93888, AIZ93900, and AIZ93901) used in the alignment exhibited sequence divergence from each other ranging from 2.1 to $15.4 \%$. Cathelicidin 5 (AGA63735 and AJA90932) also showed a sequence diversity of $1.3 \%$. There was a $3.9 \%$ diversity between the sequences of cathelicidin 6 (AJA90933 and AGA63736). There was no divergence in the sequence between cathelicidin 7 like precursor (NP 001277796) and cathelicidin 7 (AGB56852). This diversity may be due to pathogen-driven selection endowing superior antimicrobial activity which is a possible explanation of the role of cathelicidins in innate immunity of buffalo [59]. The percent variation among buffalo cathelicidins is also presented in the form of a phylogenic tree (Figure-4) which also represents the evolutionary lineage of cathelicidins.

The first cathelicidin reported in buffalo was myeloid cathelicidin which is homologous to Bos 


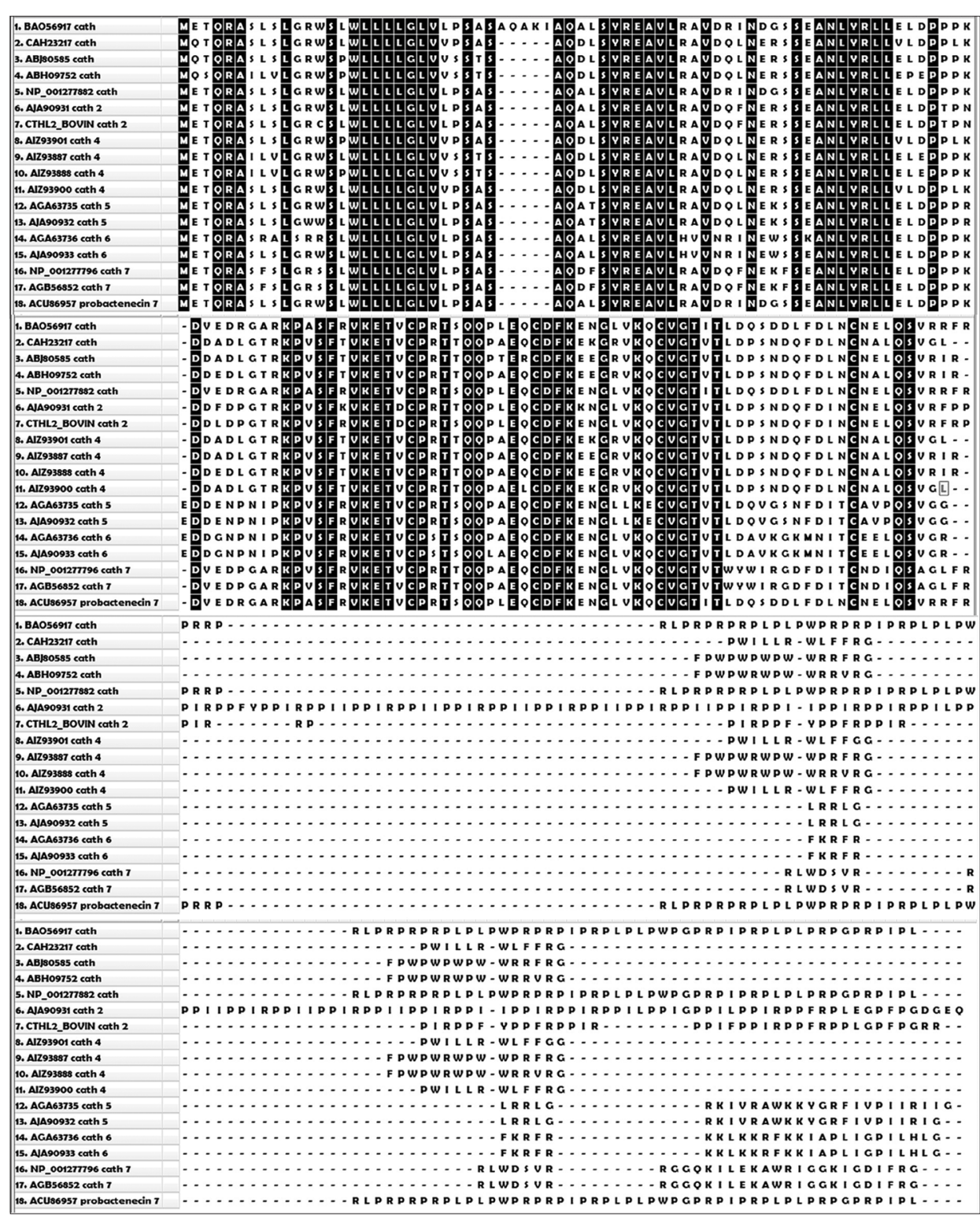

Figure-3: Alignment of buffalo cathelicidin by ClustalW of MEGA 7.0 [97]. The sequences with accession number were obtained from NCBI. Partial sequences were not included in the alignment. $100 \%$ conserved sites are toggled.

taurus cathelicidin-4 also known as indolicidin [60]. Soon after, another cathelicidin which appeared to be homologue of $B$. taurus cathelicidin-7 was identified [61]. Buffalo cathelicidin 4 shows high polymorphism and their structurally diverse homologs were also identified [59]. AMPs of these newly identified cathelicidin 4 subtypes produced antimicrobial effect by disrupting the membrane integrity of bacteria and caused blebbing, budding, and pore-like structure formation. Another three novel myeloid cathelicidins BuMAP-28, BuMAP-29, and BuMAP-34 having 28, 29 , and 34 residues, respectively, at the C-terminal putative antimicrobial domain were predicted from cDNA sequences [62]. Synthetic BuMAP-34 showed antibacterial activity against Riemerella anatipestifer, K. pneumoniae, S. typhimurium, S. aureus, and C. albicans [63]. Further, biocomputational analysis of buffalo cathelicidin 3 indicated that different types and transcript variants of cathelicidins within the same species might have resulted from positive selection during evolution in response to pressure exerted by the pathogens [64]. Some of the recent additions of buffalo cathelicidins at NCBI protein database include cathelicidin 1, 2, 3, 5, 6, and 7 and variants of cathelicidin 4 [65-73]. The presence of diverse cathelicidins in buffalo and their broad-spectrum antimicrobial activity indicates that these peptides play an important role in neutralizing invading pathogens.

\section{Hepcidin}

Hepcidin is a 25 -residue, cysteine-rich cationic AMP. It is synthesized as a precursor protein which undergoes two enzymatic cleavages to release the biologically active 25 -mer peptide $[74,75]$. There are eight cysteine residues in mature peptide which form intramolecular disulfide bonds [76]. Three forms of hepcidin with N-terminal truncations, with 20, 22, and 25 residues, have been characterized from human 
urine and all the forms were with 8 cysteine residues. Human hepcidins are active against $S$. aureus, S. epidermidis, E. coli, C. albicans, Aspergillus fumigatus, and Aspergillus niger [75]. Hepcidins have been reported from different species, and there are more than 2000 hepcidin sequences available in databases. The deduced amino acid sequence of matured buffalo hepcidin consisted of 25 amino acids with 8 cysteine residues [77] and formed a distorted beta-sheet structure with a hairpin loop (Figure-5). On alignment, matured buffalo hepcidin showed $100 \%$ amino acid sequence identity with cattle hepcidin and minimal differences with that of other mammalian species (listed in Figure-6) indicating its highly conserved nature across species. As observed in the alignment, of 25 amino acids, matured buffalo hepcidin was found to differ by $2,1,7,9,8,3,5,6,4$, and 5 amino acids from that of sheep, goat, horse, rat, mouse, pig, human, dog, monkey, and cat, respectively. Synthetic analogs showed antibacterial activity against $S$. aureus with low cytotoxic effect on buffalo lymphocytes [78]. It was already reported that hepcidin at a concentration more than 3000 -fold as found in human urine is not cytotoxic [75]. Similarly, reports on toxic concentrations of AMPs (new designed cationic AMPs and modified alpha-helical model peptide) to mammalian cells also stated that their toxicity is commonly higher by one log of magnitude than that of minimum inhibitory concentrations against bacteria $[79,80]$. Therefore, hepcidin may be targeted for the development of potent antimicrobial agent. In addition to its antimicrobial activity, hepcidin also acts as a negative regulator of iron. Hepcidin-mediated iron regulation decreases iron in blood which is thought to increase host resistance to microbial infection [81]. Overall, it indicates that hepcidin plays a crucial role in host immune defense against microbial infections.

\section{Immunomodulatory Effect and Therapeutic Potential of AMPs}

Recently, AMPs are being referred as host defense peptides by many authors owing to the fact that these peptides act mainly through immunomodulation [12]. Immunomodulatory activities of these peptides include modulation of the production of pro-inflammatory and anti-inflammatory cytokines and chemokines, recruitment of immune cells, induction of cellular differentiation and activation, regulation of cellular processes such as autophagy, apoptosis, and pyroptosis, and also the promotion of wound healing $[12,82,83]$. For example, certain family members of beta-defensin have been revealed to chemoattract immature dendritic cells and CD45RO+ CD4+ $\mathrm{T}$ cells through chemokine receptor CCR6. Further, it was also demonstrated that human beta-defensin 2 and 3 and mouse beta-defensin 4 and 14 could also chemoattract macrophages and monocytes through CCR2, a chemokine receptor expressed on monocytes, macrophages, and neutrophils [84].

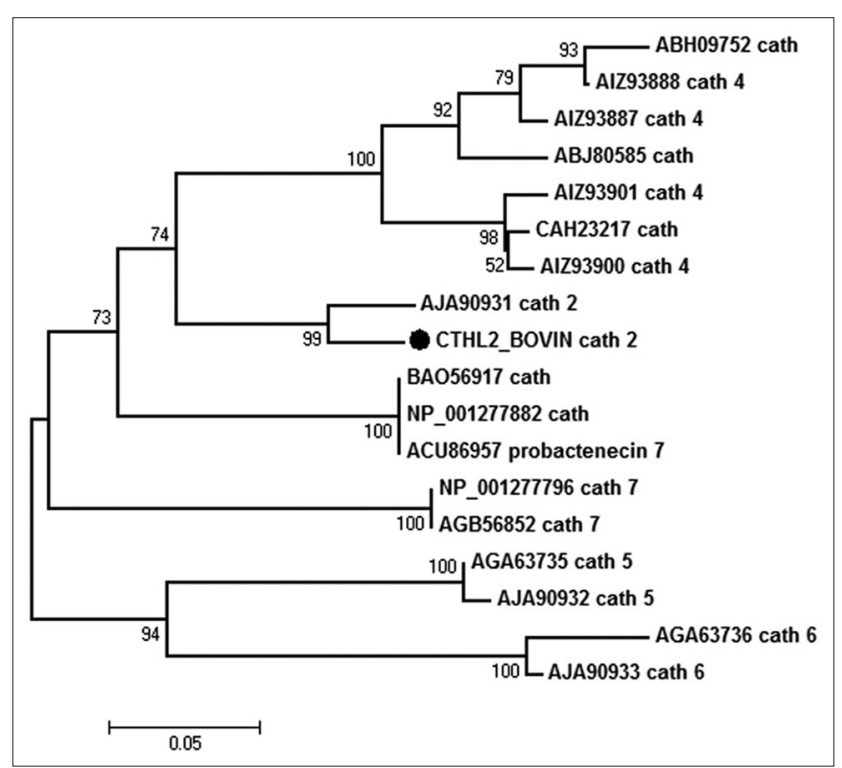

Figure-4: Phylogenetic relationships of different buffalo cathelicidins. Presented is a bootstrapped (1000 trials) neighbor-joining phylogenetic tree showing the evolutionary relationship of buffalo cathelicidin protein sequences $[100,101]$. Cattle cathelicidin 2 (CTHL2_BOVIN) was also used for comparison with buffalo cathelicidin 2 .

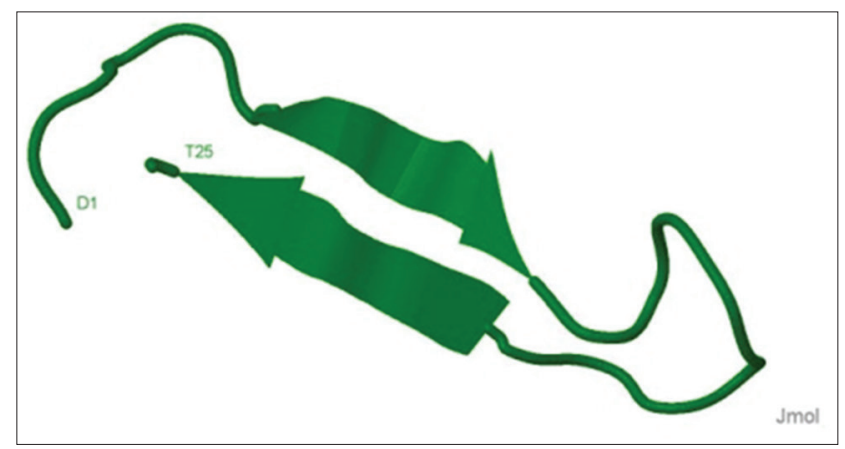

Figure-5: Predicted three-dimensional structure of buffalo hepcidin. The structure was predicted by PEPFOLD and visualized in Jmol $[98,99]$.

\begin{tabular}{|c|c|}
\hline 1. Buffalo hepcidin & DTHFP I C I FCCGCCRKGTCGMCCRT \\
\hline 2. Cattle hepcidin & DTHFP I C I FCCGCCRKGTCGMCCRT \\
\hline 3. Sheep hepcidin & DTHFP I C I FCCGCCRKGTCG I C CKT \\
\hline 4. Goat hepcidin & DTHFP I C I FCCGCCRKGTCGMCCKT \\
\hline 5. Horse hepcidin & DTHFP I C T L C C GCCNKQKCGWCCKT \\
\hline 6. Rat hepcidin & DTNFP I CLFCCKCCKNSSCGLCC I T \\
\hline 7. Mouse hepcidin & DTNFP I C I FCCKCCNNSQCG I CCKT \\
\hline 8. Pig hepcidin & DTHFP I C I FCCGCCRKA I CGMCCKT \\
\hline 9. Human hepcidin & DTHFP I C I FCCGCCHRSKCGMCCKT \\
\hline 10. Dog hepcidin & DTHFP I C I FCCGCCKTPKCGLCCKT \\
\hline 11. Monkey hepcidin & DTHFP I C I FCCGCCHRSKCGMCCRT \\
\hline 12. Cat hepcidin & DTHFP I CMFCCGCCKKARCGMCCKT \\
\hline
\end{tabular}

Figure-6: Matured peptide sequences of hepcidin. Precursor protein sequences were derived from NCBI, trimmed to 25-mer matured peptide sequences, and aligned by ClustalW of MEGA 7.0 [97]. All the sequences showed conserved 8 cysteine residues. Goat and cat hepcidin are predicted sequences.

Beta-defensins activate primary macrophages and also enhance pro-inflammatory responses to support inflammatory reactions initiated by toll-like receptor (TLR) ligands [85]. Similarly, LL37 (human cathelicidin) is known to impact the macrophages to produce 
pro-inflammatory cytokines in response to TLR agonists [86]. In addition, LL37 was shown to produce its immunomodulatory effect through activation of receptors, FPR2 and P2X7, a receptor highly expressed in immune cells $[87,88]$. Due to its multifunctionality as broad-spectrum antimicrobial against bacteria, yeasts, fungi, and viruses in addition to its cytotoxicity against cancer cells, anti-inflammatory, and immunomodulatory activities, AMPs have garnered interest as novel therapeutic agents [89]. By introducing some selective changes to the naturally occurring peptides, analogs with increased potency against microorganisms but reduced toxicity toward mammalian cells have been developed [90]. For designing novel antibiotics using the native AMPs as templates, some of the strategies involved are to change from L- to D-amino acids, C-terminal amidation, and $\mathrm{N}$-acetylation [91]. For example, C-amidation and $\mathrm{N}$-acetylation of octapeptide (RGKAKCCK), derived from human beta-defensin 1, significantly improved its antimicrobial activity with no toxicity to human cell even at high concentration and therefore appropriate for therapeutic applications [92]. Several AMPs are currently being evaluated not only for its antimicrobial effect but also as new pharmacological agents to modulate the immune response, promote wound healing, and prevent post-surgical adhesions [93]. It had been demonstrated that application of hBD2 or hBD3 promotes the healing of $S$. aureus-contaminated bone defects [94]. Similarly, LL-37 is developed for the treatment of chronic leg ulcers, and its clinical trial showed that LL-37 has a significantly improved healing rate compared to placebo $[95,96]$.

\section{Conclusion and Future Prospects}

With increased interests on AMPs, the list of buffalo AMPs is ever expanding. Many of the studies have focussed on the characterization of cDNA and its deduced peptide sequence. However, isolation and analysis of antimicrobial activity of these peptides are very limited as compared to other species. There are only few reports on the antimicrobial activity of synthetic analogs of buffalo AMP. Moreover, experimental studies on the inducibility of the genes encoding these peptides in buffalo are also lacking. Therefore, functional studies of these peptides along with its expression analysis during encounter with pathogenic microbes will be helpful in better understanding of the immune defense system of buffalo. For therapeutic applications, synthetic analogs of buffalo AMPs may be developed following some strategies to modify the naturally occurring peptides to improve its efficacy and host cell toxicity. Incorporation of unnatural amino acids (D-amino acids) at suitable positions may be done to enhance resistance of AMPs to proteases and sustain their activity for longer duration. Modifications in the synthetic analogs to get shorter length as compared to native sequences but with improved activity may also help to reduce the costs of production. Further, AMPs can also be synthesized in dendrimeric form to enhance its antimicrobial effect. The immunomodulatory effect of these AMPs (or synthetic analogs) on host body may also be investigated by evaluating the induction of chemokines, anti-inflammatory properties, and activation of signaling pathways.

\section{Authors' Contributions}

All the authors conceptualized the manuscript. Both KVC and DT drafted the manuscript. SK has given the intellectual suggestions. $\mathrm{KVC}$ has done the software analysis part. DT and SK critically reviewed the manuscript. All the authors have read and approved the final version of the manuscript.

\section{Acknowledgments}

Authors acknowledge the support of information systems of ICAR-Indian Veterinary Research Institute, Bareilly, for free access to literature and ICAR-Directorate of Coldwater Fisheries Research for the facilities and internet service required for drafting this manuscript.

\section{Competing Interests}

The authors declare that they have no competing interests.

\section{References}

1. Singh, V.K., More, T. and Kumar, S. (2004) Separation of cationic proteins and antibiotic peptides from buffalo polymorphonuclear cells. Buffalo J., 2: 173-182.

2. Yang, S.C., Lin, C.H., Sung, C.T. and Fang, J.Y. (2014) Antibacterial activities of bacteriocins: Application in foods and pharmaceuticals. Front Microbiol., 5: 241.

3. Chugh, J.K. and Wallace, B.A. (2001) Peptaibols: Models for ion channels. Biochem. Soc. Trans., 29: 565-570.

4. Boman, H.G., Faye, I., Lee, J.Y., Gudmundsson, G.H. and Lidholm, D.A. (1991) Cell-free immunity in Cecropia. A model system for antibacterial proteins. Eur. J. Biochem., 201: 23-31

5. Masso-Silva, J.A. and Diamond, G. (2014) Antimicrobial peptides from fish. Pharmaceuticals (Basel), 7: 265-310.

6. Zasloff, M. (1987) Magainins, a class of antimicrobial peptides from Xenopus skin: isolation, characterization of two active forms, and partial cDNA sequence of a precursor. Proc. Natl. Acad. Sci. USA, 84: 5449-5453.

7. Amiche, M., Seon, A.A., Pierre, T.N. and Nicolas, P. (1999) The dermaseptin precursors: A protein family with a common preproregion and a variable C-terminal antimicrobial domain. FEBS Lett., 456: 352-356.

8. Zhang, G. and Sunkara, L.T. (2014) Avian antimicrobial host defense peptides: From biology to therapeutic applications. Pharmaceuticals, 7: 220-246.

9. Zasloff, M. (2002) Antimicrobial peptides of multicellular organisms. Nature, 415: 389-395.

10. Schauber, J. and Gallo, R.L. (2008) Antimicrobial peptides and the skin immune defense system. J. Allergy Clin. Immunol., 122: 261-266.

11. Malmsten, M. (2016) Interactions of antimicrobial peptides with bacterial membranes and membrane components. Curr. Top. Med. Chem., 16: 16-24.

12. Hancock, R.E.W., Haney, E.F. and Gill, E.E. (2016) The immunology of host defence peptides: beyond antimicrobial activity. Nat. Rev. Immunol., 16: 321-334.

13. Buck, C.B., Day, P.M., Thompson, C.D., Lubkowski, 
J., Lu, W., Lowy, D.R. and Schiller, J.T. (2006) Human alpha-defensins block papillomavirus infection. Proc. Natl. Acad. Sci. US A., 103: 1516-1521.

14. Currie, S.M., Findlay, E.G., McFarlane, A.J., Fitch, P.M., Böttcher, B., Colegrave, N., Paras, A., Jozwik, A., Chiu, C., Schwarze, J. and Davidson, D.J. (2016) Cathelicidins have direct antiviral activity against respiratory syncytial virus in vitro and protective function in vivo in mice and humans. J. Immunol., 196: 2699-2710.

15. Rozek, T., Wegener, K.L., Bowie, J.H., Olver, I.N., Carver, J.A., Wallace, J.C. and Tyler, M.J. (2000) The antibiotic and anticancer active aurein peptides from the Australian bell frogs Litoria aurea and Litoria raniformis the solution structure of aurein 1.2. Eur. J. Biochem., 267: 5330-5341.

16. Gaspar, D., Freire, J.M., Pacheco, T.R., Barata, J.T. and Castanho, M.A.R.B. (2015) Apoptotic human neutrophil peptide-1 anti-tumor activity revealed by cellular biomechanics. Biochim. Biophys. Acta Mol. Cell Res., 1853: 308-316.

17. Cunliffe, R.N. and Mahida, Y.R. (2004) Expression and regulation of antimicrobial peptides in the gastrointestinal tract. J. Leukocyte Biol., 75: 49-58.

18. Nguyen, T.X., Cole, A.M. and Lehrer, R.I. (2003) Evolution of primate theta-defensins: A serpentine path to sweet tooth. Peptides, 24: 1647-1654.

19. Lehrer, R.I. and Lu, W. (2012) Alpha-defensins in human innate immunity. Immunol. Rev., 245: 84-112.

20. Li, D., Zhang, L., Yin, H., Xu, H., Satkoski, T.J., Smith, D.G., Li, Y., Yang, M. and Zhu, Q. (2014) Evolution of primate $\alpha$ and $\theta$ defensins revealed by analysis of genomes. Mol. Biol. Rep., 41: 3859-3866.

21. Ganz, T. and Lehrer, R.I. (1994) Defensins. Curr. Opin. Immunol., 6: 584-589.

22. Diamond, G., Zasloff, M., Eck, H., Brasseur, M., Maloy, W.L. and Bevins, C.L. (1991) Tracheal antimicrobial peptide, a cysteine-rich peptide from mammalian tracheal mucosa: Peptide isolation and cloning of cDNA. Proc. Natl. Acad. Sci. U S A, 88: 3952-6.

23. Sandeep, K., More, T. and Renu (2006) Biochemical characterization of antimicrobial peptides buffalo tracheal epithelium. J. Immunol. Immunopathol., 8: 30-34.

24. Hiemstra, P.S. (2001) Epithelial antimicrobial peptides and proteins: Their role in host defence and inflammation. Paediatr. Respir. Rev., 2: 306-310.

25. Newhouse, M.T. and Bienenstock, J. (1989) Respiratory tract defense mechanisms. In: Baum, G.L., Wolinsky, E., editors. Textbook of Pulmonary Disease. Little, Brown \& Co. Boston, Mass. p21-47.

26. Mossallam, A.A.A., Soheir, M., Nahas, E., Sabry, N.M., Mahfouz, E.R. and Hassan, A.A. (2011) Partial characterization of three-defensin gene transcripts in river buffalo and cattle. Afr. J. Biotechnol., 10: 11388-11396.

27. Das, H. and More, T. (2007) Tracheal Antimicrobial Peptide (Bubalus bubalis). NCBI Accession Number: Abn72272.

28. Das, H., Lateef, A., Desai, M.C., Chandel, B.S. and Parsani, H.R. (2014) Tracheal Antimicrobial Peptide (Bubalus bubalis). NCBI Accession Number: AIU56269.

29. Stolzenberg, E.D., Anderson, G.M., Ackermann, M.R. and Whitlock, R.H. (1997) Epithelial antibiotic induced in states of disease. Proc. Natl. Acad. Sci., 94: 8686-8690.

30. Schonwetter, B.S., Stolzenberg, E.D. and Zasloff, M.A. (1995) Epithelial antibiotics induced at sites of inflammation. Science, 267: 1645-1648.

31. Isobe, N., Hosoda, K. and Yoshimura, Y. (2009) Immunolocalization of lingual antimicrobial peptide (LAP) in the bovine mammary gland. Anim. Sci. J., 80: 446-450.

32. Das, H., Lateef, A., Chandel, B.S., Desai, M.C. and Parsani, H.R. (2014) Lingual Antimicrobial Peptide (Bubalus bubalis). NCBI Accession Number: AIU56268.

33. Das, H. and More, T. (2016) Lingual Antimicrobial Peptide Precursor (Bubalus bubalis). NCBI Accession Number:

\section{LAP BUBBU.}

34. Anbu, K.A., More, T. and Kumar, A. (2002) Characterization of cationic proteins and peptides from buffalo tongue epithelium. Buffalo J., 2: 211-216.

35. Kalita, D.J. and Kumar, A. (2009) Molecular cloning and characterization of lingual antimicrobial peptide cDNA of Bubalus bubalis. Res. Vet. Sci., 86: 91-97.

36. Das, H., Ahmed, S.U., Thakuria, D., Pathan, M.M., Latif, A., Roy, S.K. and More, T. (2009) Lingual antimicrobial peptide expresses in buffalo mammary gland. Anim. Biotechnol., 20: 75-79.

37. Joseph, D. and More, T. (2011) Molecular characterization of lingual antimicrobial peptide in the female reproductive tract of Buffalo. Vet. World, 4: 120-123.

38. Lehrer, R.I., Rosenman, M., Harwig, S.S.S.L., Jackson, R. and Eisenhauer, P. (1991) Ultrasensitive assays for endogenous antimicrobial polypeptides. J. Immunol. Methods, 137: 67-173.

39. Ganz, T. (2003) The role of antimicrobial peptides in innate immunity. Integr. Comp. Biol., 43: 300-304.

40. Graf, M., Mardirossian, M., Nguyen, F., Seefeldt, A.C., Guichard, G., Scocchi, M., Innis, C.A. and Wilson, D.N. (2017) Proline-rich antimicrobial peptides targeting protein synthesis. Nat. Prod. Rep., 34: 702-711.

41. Gennaro, R., Zanetti, M., Benincasa, M., Podda, E. and Miani, M. (2002) Pro-rich antimicrobial peptides from animals: Structure, biological functions and mechanism of action. Curr. Pharm. Des., 8: 763-778.

42. Suh, J.Y., Lee, Y.T., Park, C.B., Lee, K.H., Kim, S.C. and Choi, B.S. (1999) Structural and functional implications of a proline residue in the antimicrobial peptide gaegurin. Eur. J. Biochem., 266: 665-674.

43. Park, S.H., Kim, H.E., Kim, C.M., Yun, R.P., Choi, E.C. and Lee, B.J. (2002) Role of proline cysteine and a disulphide bridge in the structure and activity of the antimicrobial peptide gaegurin 5. Biochem. J., 368: 171-182.

44. Kalita, D.J., Kumar, A. and Kumar, S. (2009) Structurefunction studies of Bubalus bubalis lingual antimicrobial peptide analogs. Vet. Res. Commun., 33: 49-161.

45. Das, H., Ahmed, S.U., Shukla, S.K., Shukla, S., Latif, A. and Sharma, D. (2010) Two $\beta$ defensin cationic peptides from mastitic milk of Bubalus bubalis. Asian J. Anim. Sci., 4: 1-12.

46. Bera, B.C., Chaudhury, P., Bhattacharya, D., Bera, A.K. and Das, S.K. (2007) Cloning, sequencing and expression of cDNA of bovine neutrophil $\beta$-defensin from water buffalo (Bubalus bubalis). Int. J. Immunogenet., 34: 173-179.

47. Das, D.K., Sharma, B., Mitra, A. and Kumar, A. (2005) Molecular cloning and characterization of $\beta-\beta$ cDNA expressed in distal ileum of buffalo (Bubalus bubalis). DNA Seq., 16: 16-20.

48. Tarver, A.P., Clark, D.P., Diamond, G., Russell, J.P., Erdjument-Bromage, H., Tempst, P., Cohen, K.S., Jones, D.E., Sweeney, R.W., Wines, M., Hwang, S. and Bevins, C.L. (1998) Enteric $\beta$-defensin: Molecular cloning and characterization of a gene with inducible intestinal epithelial cell expression associated with Cryptosporidium parvum infection. Infect. Immun., 66: 1045-1056.

49. Kościuczuk, E.M., Lisowski, P., Jarczak, J., Strzałkowska, N., Jóźwik, A., Horbańczuk, J., Krzyżewski, J., Zwierzchowski, L. And Bagnicka, E. (2012) Cathelicidins: Family of antimicrobial peptides. A review. Mol. Biol. Rep., 39: 10957-10970.

50. Zanetti, M., Gennaro, R. and Romeo, D. (1995) Cathelicidins: A novel protein family with a common proregion and a variable $\mathrm{C}$-terminal antimicrobial domain. FEBS Lett., 374: 1-5.

51. Ritonja, A., Kopitar, M., Jerala, R. and Turk, V. (1989) Primary structure of a new cysteine proteinase inhibitor from pig leucocytes. FEBS Lett., 255: 211-214.

52. Brogden, K.A. (2005) Antimicrobial peptides: Pore formers or metabolic inhibitors in bacteria? Nat. Rev. Microbiol., 
3: 238-250.

53. Hsu, C.H., Chen, C., Jou, M.L., Lee, A.Y., Lin, Y.C., Yu, Y.P., Huang, W.T. and Wu, S.H. (2005) Structural and DNA-binding studies on the bovine antimicrobial peptide, indolicidin: Evidence for multiple conformations involved in binding to membranes and DNA. Nucleic Acids Res., 33: 4053-4064.

54. Marchand, C., Krajewski, K., Lee, H.F., Antony, S., Johnson, A.A., Amin, R., Roller, P., Kvaratskhelia, M. and Pommier, Y. (2006) Covalent binding of the natural antimicrobial peptide indolicidin to DNA abasic sites. Nucleic Acids Res., 34: 5157-5165.

55. Silva, T. and Gomes, M.S. (2017) Immuno-stimulatory peptides as a potential adjunct therapy against intra-macrophagic pathogens. Molecules, 22: 1297.

56. Gennaro, R., Skerlavaj, B. and Romeo, D. (1989) Purification, composition, and activity of two bactenecins, antibacterial peptides of bovine neutrophils. Infect Immun., 57: 3142-3146.

57. Das, H., Sharma, B. and Kumar, A. (2007) Identification and molecular characterization of cathelin-like prepro region from Bubalus bubalis. J. Appl. Anim. Res., 31: 213-221.

58. Kalita, D.J. (2015). Characterization of cathelicidin gene from buffalo (Bubalus bubalis). Afr. J. Biotechnol., 14: 758-763.

59. Brahma, B., Patra, M.C., Karri, S., Chopra, M., Mishra, P., De, B.C., Kumar, S., Mahanty, M., Thakur, K., Poluri, K.M., Datta, T.K. and De, S. (2015) Diversity, antimicrobial action and structure activity relationship of Buffalo cathelicidins. PLoS One, 10(12): e0144741.

60. Das, H., Sharma, B. and Kumar, A. (2006) Cloning and characterization of novel cathelicidin cDNA sequence of Bubalus bubalis homologous to Bos taurus cathelicidin-4. DNA Seq., 17: 407-414.

61. Das, H., Ahmed, S.U. and More, T. (2008) Molecular characterization of cDNA encoding $B$. taurus cathelicidin-7 like antibiotic peptide from bone marrow cells of Bubalus bubalis. DNA Seq., 19: 347-356.

62. Panicker, V.P. and George, S. (2013) Identification of three novel myeloid cathelicidin cDNAs and their predicted peptides in buffalo (Bubalus bubalis). Indian J. Biochem. Biophys. 50: 273-277.

63. Panicker, V.P. and George, S. (2016) Chemistry and antimicrobial potential of the buffalo myeloid cathelicidin, BuMAP-34. Int. J. Pept. Res. Ther., 22: 413-420.

64. Hussain, S., Mukhopadhyay, C.S., Kumar, B.V.S. and Kaur, S. (2016) Phylogenetic characterization of novel cathelicidin from Indian water buffalo. Indian J. Biotech., 15: 495-506.

65. Brahma, B., Karri, S., Chopra, M., Patra, M.C., Kumar, S., De, B.C., Mahanty, S., Datta, T.K. and De, S. (2015) Cathelicidin-1 (Bubalus bubalis). NCBI Accession Number: AJA90930.

66. Brahma, B., Karri, S., Chopra, M., Patra, M.C., Kumar, S., De, B.C., Mahanty, S., Datta, T.K. and De, S. (2015) Cathelicidin-2 (Bubalus bubalis). NCBI Accession No. AJA90931.

67. Hussain, S. and Mukhopadhyay, C.S. (2014) Cathelicidin (Bubalus bubalis). NCBI Accession Number: BAO56917.

68. Varuna, P.P., Sisilamma, G., Uma, R., Abraham, P., Jayavardhanan, K.K. and Chinnu, M.V.(2013)Cathelicidin-5 (Bubalus bubalis). NCBI Accession Number: AGA63735.

69. Varuna, P.P., Sisilamma, G., Uma, R., Pellissery, A.J., Jayavardhanan, K.K., Divya, P.D. and Ciby, S. (2014) Cathelicidin-6 (Bubalus bubalis). NCBI Accession Number: AGA63736.

70. Varuna, P.P., Sisilamma, G., Uma, R., Pellissery, A.J. and Jayavardhanan, K.K. (2013) Cathelicidin-7 (Bubalus bubalis). NCBI Accession No. AGB56852.

71. Brahma, B., Karri, S., Chopra, M., Patra, M.C., Kumar, S., De, B.C., Mahanty, S., Datta, T.K. and De, S. (2015) Cathelicidin-4 (Bubalus bubalis). NCBI Accession Number:
AIZ93892.

72. Mossallam, A.A.A., El Nahas, S.M. and Sabry, N.M. (2016) Cathelicidin-4, Partial (Bubalus bubalis). NCBI Accession Number: ACT82508.

73. Brahma, B., Karri, S., Chopra, M., Patra, M.C., Kumar, S., De, B.C., Mahanty, S., Datta, T.K. and De, S. (2015) Cathelicidin-4 (Bubalus bubalis). NCBI Accession Number: AIZ93882.

74. Krause, A., Neitz, S., Mägert, H.J., Schulz, A., Forssmann, W.G., Schulz-Knappe, P. and Adermann, K. (2000) LEAP-1, a novel highly disulphide-bonded human peptide, exhibits antimicrobial activity. FEBS Lett., 480: 147-150.

75. Park, C.H., Valore, E.V., Waring, A.J. and Ganz, T. (2001) Hepcidin, a urinary antimicrobial peptide synthesized in the liver. J. Biol. Chem., 276: 7806-7810.

76. Hunter, H.N., Fulton, D.B., Ganz, T. and Vogel, H.J. (2002) The solution structure of human hepcidin, a peptide hormone with antimicrobial activity that is involved in iron uptake and hereditary hemochromatosis. J. Biol. Chem., 277: 37597-37603.

77. Khangembam, V.C. and Kumar, A. (2011) Buffalo hepcidin: Characterization of cDNA and study of antimicrobial property. Vet. Res. Commun., 35: 79-87.

78. Chanu, K.V., Kumar, A. and Kumar, S. (2011) Structure activity relationship of buffalo antibacterial hepcidin analogs. Indian J. Biochem. Biophys., 48: 325-330.

79. Hollmann, A., Martínez, M., Noguera, M.E., Augusto, M.T., Disalvo, A., Santos, N.C., Semorile, L. and Maffía, P.C. (2016) Role of amphipathicity and hydrophobicity in the balance between hemolysis and peptide-membrane interactions of three related antimicrobial peptides. Colloids Surf. B. Biointerfaces, 141: 528-536.

80. Son, M., Lee, Y., Hwang, H., Hyun, S. and Yu, J. (2013) Disruption of interactions between hydrophobic residues on nonpolar faces is a key determinant in decreasing hemolysis and increasing antimicrobial activities of $\alpha$-helical amphipathic peptides. Chem. Med. Chem., 8: 1638-1642.

81. Nemeth, E., Tuttle, M.S., Powelson, J., Vaughn, M.B., Donovan, A., Ward, D.M., Ganz, T. and Kaplan, J. (2004) Hepcidin regulates cellular Iron efflux by binding to ferroportin and inducing its internalization. Science, 306: 2090-2093.

82. Mansour, SC., Pena, O.M. and Hancock, R.E. (2014) Host defense peptides: Frontline immunomodulators. Trends Immunol., 35: 443-450.

83. Otvos, L. Jr. (2016) Immunomodulatory effects of anti-microbial peptides. Acta Microbiol. Immunol. Hung., 63: 257-277.

84. Röhrl, J., Yang, D., Oppenheim, J.J. and Hehlgans, T. (2010) Human beta-defensin 2 and 3 and their mouse orthologs induce chemotaxis through interaction with CCR2. $J$. Immunol., 184: 6688-6694.

85. Barabas, N., Röhrl, J., Holler, E. and Hehlgans, T. (2013) Beta-defensins activate macrophages and synergize in pro-inflammatory cytokine expression induced by TLR ligands. Immunobiology, 218: 1005-1011.

86. Mookherjee, N., Brown, K.L., Bowdish, D.M., Doria, S., Falsafi, R., Hokamp, K., Roche, F.M., Mu, R., Doho, G.H., Pistolic, J., Powers, J.P., Bryan, J., Brinkman, F.S. and Hancock, R.E. (2006) Modulation of the TLR-mediated inflammatory response by the endogenous human host defense peptide LL-37. J. Immunol., 176: 2455-2464.

87. Tripathi, S., Wang, G., White, M., Rynkiewicz, M., Seaton, B. and Hartshorn, K. (2015) Identifying the critical domain of LL-37 involved in mediating neutrophil activation in the presence of influenza virus: Functional and structural analysis. PLoS One, 10: e0133454.

88. Elssner, A., Duncan, M., Gavrilin, M. and Wewers, M.D. (2004) A novel P2X7 receptor activator, the human cathelicidin-derived peptide LL37, induces IL-1 processing and release. J. Immunol., 172: 4987-4994. 
89. Kang, H.K., Kim, C., Seo, C.H. and Park, Y. (2017) The therapeutic applications of antimicrobial peptides (AMPs): A patent review. J. Microbiol., 55: 1-12.

90. Conlon, J.M. (2004) The therapeutic potential of antimicrobial peptides from frog skin. Rev. Med. Microbiol., 15: $17-25$.

91. Falanga, A., Nigro, E., De Biasi, M.G., Daniele, A., Morelli, C., Galdiero, S. and Scudiero, O. (2017) Cyclic peptides as novel therapeutic microbicides: Engineering of human defensin mimetics. Molecules, 22: 1217.

92. Stange, E., Schroeder, B. and Wehkamp, J. (2015) Antimicrobial Peptides. WO2013132005A1.

93. Mahlapuu, M., Håkansson, J., Ringstad, L. and Björn, C. (2016) Antimicrobial peptides: An emerging category of therapeutic agents. Front. Cell. Infect. Microbiol., 6: 194.

94. Lee, P.H., Chen, M.Y., Lai, Y.L., Lee, S.Y. and Chen, H.L. (2017) Human beta-defensin-2 and -3 mitigate the negative effects of bacterial contamination on bone healing in rat calvarial defect. Tissue Eng.Part A.

95. Li, J., Koh, J.J., Liu, S., Lakshminarayanan, R., Verma, C.S. and Beuerman, R.W. (2017) Membrane active antimicrobial peptides: Translating mechanistic insights to design. Front.
Neurosci., 11: 73.

96. Lee, D.K., Bhunia, A., Kotler, S.A. and Ramamoorthy, A. (2015) Detergent-type membrane fragmentation by MSI78, MSI-367, MSI-594, and MSI-843 antimicrobial peptides and inhibition by cholesterol: A solid-state nuclear magnetic resonance study. Biochemistry, 54: 1897-1907.

97. Kumar, S., Stecher, G. and Tamura, K. (2016) MEGA7: Molecular evolutionary genetics analysis version 7.0 for bigger datasets. Mol. Biol. Evol., 33: 1870-1874.

98. Thévenet, P., Shen, Y., Maupetit, J., Guyon, F., Derreumaux, P. and Tufféry. P. (2012) PEP-FOLD: An updated denovo structure prediction server for both linear and disulfide bonded cyclic peptides. Nucleic Acids Res., 40: W288-W293.

99. Jmol. (2010) Jmol: An Open-Source Java Viewer for Chemical Structures in 3D. Available from: http://www. jmol.org/. Last accessed on 11-12-2017.

100. Felsenstein, J. (1985) Confidence limits on phylogenies: An approach using the bootstrap. Evolution, 39: 783-791.

101. Saitou, N. and Nei, M. (1987) The neighbour-joining method: A new method for reconstructing phylogenetic trees. Mol. Biol. Evol., 4: 406-425. 